\title{
Inventory Model for Downward Substitution in Two-echelon Supply Chain under Stochastic Demand
}

\author{
Yan-hong Qin ${ }^{1}$, Xing-hong Qin ${ }^{2}$ and Qing $W u^{3}$ \\ ${ }^{1}$ School of Management, Chongqing Jiaotong University, Chongqing, 400074, China \\ ${ }^{2}$ School of Economics and Management, Tongji University, Shanghai, 200092, China \\ ${ }^{3}$ School of Economics and Management, Electronic Science and Technology University, Sichuan, 610054, China
}

Received: 15 Oct. 2012, Revised: 22 Jan. 2013, Accepted: 25 Jan. 2013

Published online: 1 Jun. 2013

\begin{abstract}
The substitution between products is a common phenomenon in supply chain management when customers find their favorite product unavailable. Product substitution can improve the availability of different products and thus improve the customer service level, especially when the high-end product substitutes for the low-end product. In this paper, we construct profit model of downward substitution strategy and apply the optimal theory to compute the optimal order quantity and the maximal profit under this strategy in the first place, and then some relationships between product wholesale price, sale price, net salvage value and optimal order quantity are investigated. By analyzing the relationship between these different factors, we can obtain the compact of substitution strategy on product sale, which can provide management insight to real sale activity.
\end{abstract}

Keywords: Downward substitution, supply chain, stochastic demand, inventory

\section{Introduction}

With the economic competition is more and more fierce, each enterprise must provide customers with better service to obtain more market share. But in actual sale process, the phenomenon of stock-outs often occur due to insufficient inventory supply, so the customers mainly have two actions: giving up buying the faithful type of products or choose other products to substitute to meet their demand (Anupindi and Data, 1998). When one product is sold out, we can use the other ones to substitute for it or provide customers with the same products after restocking. Product substitution is an effective method to satisfy various demands as well as improve customer services. Recently, research on substitution inventory has been a hot issue. Generally speaking, only high-end product can substitute for low-end product, i.e. downward substitution. As following, we will discuss multi-product inventory strategy under downward substitution. Dong and Xu (2002) and Braglia and Zavanella (2003) studied the inventory management of substitution, and they constructed relative inventory model to analyze the final customer demand under downward substitution. Kuk (2004) and Hassini (2005) constructed multi-product and multi-echelon inventory model for substitution products by considering inventory cost, purchase cost and shortage cost from sale person's perspective, but the paper didn't provide the specific algorithm to get the optimal order quantity. Dong and Xu (2007) and Khouja and Goyal (2008) researched price and delivery strategies under oligarch market and constructed relative strategy model for the demand sensitive to price and time, although they put out an algorithm for optimal solution, they didn't make some analysis and comparison for their solutions. Deniz and Karaesmen (2010) set model for substituted perishable products in a discrete-time supply chain, and the demand for substituted products were assumed to be independent of different ages. Huang and Zhao (2010) presented an inventory model allowing for free and full substitution among multiple products and provided the necessary and sufficient optimality conditions in a single-period newsboy framework. To complete the research problem, the main work of this paper is as following: under the assumption of downward substitution, we will construct profit model with substitution and apply the optimal theory to compute the optimal order quantity in the first place, and then we will analyze some relationships among optimal order quantity,

\footnotetext{
* Corresponding author e-mail: qinyanhong24@163.com
} 
product wholesale price, sale price, net salvage value, average demand and the demand variation. By analyzing the relationship between these different factors, we can know the compact of substitution strategy on products sale, which can provide theory guidance to real sale activity.

\section{Model development}

$i(i=1,2)$ : the product index. $D_{i} \geq 0$ : the stochastic demand of product $i . f(\cdot)$ denote the joint distribution density of $\left(D_{1}, D_{2}\right), f_{i}(\cdot), F_{i}(\cdot)$ denotes the density function and the distribution function of $D_{i}$ respectively. $p_{i}$ : the unit sale price of product $i$. $c_{i}$ : the unit wholesale price of product $D_{i}$. $\pi_{i}$ : the unit shortage cost of product $D_{i}$. $s_{i}$ : the unit salvage of product $D_{i}$. $h_{i}$ : the unit inventory holding cost of product $D_{i}$. $Q_{i}$ : the order quantity of product $D_{i} . v_{i}$ : the surplus value after deducting inventory cost from unit salvage value $v_{i}=s_{i}-h_{i}$, and $r_{i}=p_{i}+\pi_{i}$.

We only consider two products demand of same kind but with different quality, i.e. the high-end product can substitute for the low-end one to meet the demand of the latter one. The relative assumptions are as following:

(1) There are two products, i.e. product 1 and product 2 , and product 1 is assumed to have higher quality than the other one, so we can substitute product 2 with product 1 to satisfy the demand for product 2 when product 1 have enough inventory but product 2 are stock-out. An additional explanation is necessary here: the sum of unit price of product 2 and its unit salvage value isn't lower than the salvage value of product 1 , i.e. $r_{2}=p_{2}+\pi_{2} \geq v_{1}$, which indicates we can get profits by substituting product 2 with product 1 .

(2) The sale price of product 1 equal to the price of product 2 when we substitute product 2 with product 1 .

(3) The sum of sale price and the loss of stock out isn't less than its sale price, the unit sale price of each product isn't less than its wholesale price, and unit wholesale price isn't lower than its unit salvage value, i.e. $r_{i} \geq p_{i} \geq c_{i} \geq$ $v_{i}>0, i=1,2$.

(4) $p_{1} \geq p_{2}, \pi_{1} \geq \pi_{2}, c_{1} \geq c_{2}, v_{1} \geq v_{2}$, which means the unit sale price of product 1 is higher than product 2 , the loss from shortage of product 1 is higher than product 2 , the unit wholesale price of product 1 is higher than product 2 , and the salvage value of product 1 is higher than product 2.

From the above assumptions, once the product 2 is stock-out, the substitution strategy will be adopted. $P\left(Q_{1}, Q_{2}\right)$ denote the total expected revenue of product 1 and product 2 , so we can get expect profit of seller as following: $P\left(Q_{1}, Q_{2}\right)=$

$$
\begin{gathered}
E\left\{p_{1} \min \left(D_{1}, Q_{1}\right)+p_{2} \min \left[D_{2},\left(Q_{2}, Q_{1}-D_{1}\right)^{+}\right]-c_{1} Q_{1}\right. \\
-c_{2} Q_{2}+v_{1} \max \left[0, \min \left(Q_{1}-D_{1}, Q_{1}+Q_{2}-D_{1}-D_{2}\right)\right] \\
+v_{2} \max \left(0, Q_{2}-D_{2}\right)-\pi_{1} \max \left(0, D_{1}-Q_{1}\right)-
\end{gathered}
$$

$$
\left.\pi_{2} \max \left[0, \min \left(D_{2}-Q_{2}, D_{1}+D_{2}-Q_{1}-Q_{2}\right)\right]\right\}
$$

By taking the denotations into above formula, we can get the following equation and some conclusions.

$$
\begin{aligned}
& P\left(Q_{1}, Q_{2}\right)=p_{1}\left[\int_{0}^{Q_{1}} x f_{1}(x) d x+\int_{Q_{1}}^{\infty} Q_{1} f_{1}(x) d x\right] \\
& +p_{2}\left[\int_{0}^{Q_{1}} \int_{0}^{Q_{1}+Q_{2}-x}(y f(x, y) d y+\right. \\
& \left.\int_{Q_{1}+Q_{2}-x}^{\infty}\left(Q_{1}+Q_{2}-x\right) f(x, y) d y\right) d x \\
& +p_{2}\left[\int _ { 0 } ^ { Q _ { 1 } } \left(\int_{0}^{Q_{1}+Q_{2}-x} y f(x, y) d y+\right.\right. \\
& \left.\int_{Q_{1}+Q_{2}-x}^{\infty}\left(Q_{1}+Q_{2}-x\right) f(x, y) d y\right) d x \\
& \left.\int_{Q_{1}}^{\infty}\left(\int_{0}^{Q_{2}} y f(x, y) d y+\int_{Q_{2}}^{\infty} Q_{2} f(x, y) d y\right) d x\right] \\
& -c_{1} Q_{1}-c_{2} Q_{2}+v_{1}\left[\int_{0}^{Q_{2}} \int_{0}^{Q_{1}}\left(Q_{1}-x\right) f(x, y) d x d y\right. \\
& +\int_{Q_{2}}^{\infty} \int_{0}^{Q_{1}+Q_{2}-y}\left(Q_{1}+Q_{2}-x-y\right) f(x, y) d x d y \\
& \left.+v_{2} \int_{0}^{Q_{2}}\left(Q_{2}-y\right) f_{2}(y) d y-\pi_{1} \int_{Q_{1}}^{\infty}\left(x-Q_{1}\right) f_{1}(x) d x\right] \\
& -\pi_{2}\left[\int_{0}^{Q_{1}} \int_{Q_{1}+Q_{2}-x}^{\infty}\left(x+y-Q_{1}-Q_{2}\right) f(x, y) d y d x\right. \\
& \left.+\int_{Q_{1}}^{\infty} \int_{Q_{2}}^{\infty}\left(y-Q_{2}\right) f(x, y) d y d x\right] \\
& =p_{1} \int_{0}^{\infty} x f_{1}(x) d x-r_{1} \int_{Q_{1}}^{\infty}\left(x-Q_{1}\right) f_{1}(x) d x+p_{2} \int_{0}^{\infty} y f_{2}(y) d y \\
& -r_{2}\left[\int_{0}^{Q_{1}} \int_{Q_{1}+Q_{2}}^{\infty}\left(x+y-Q_{1}-Q_{2}\right) f(x, y) d y d x+\right. \\
& \left.\int_{Q_{1}}^{\infty} \int_{Q_{2}}^{\infty} d y d x+\int_{Q_{2}}^{\infty} \int_{Q_{2}}^{\infty}\left(y-Q_{2}\right) f(x, y) d y d x\right] \\
& -c_{1} Q_{1}-c_{2} Q_{2}+v_{1}\left[\int_{0}^{Q_{2}} \int_{0}^{Q_{1}}\left(Q_{1}-x\right) f(x, y) d x d y\right. \\
& \left.+\int_{Q_{2}}^{Q_{1}+Q_{2}} \int_{0}^{Q_{1}+Q_{2}-y}\left(Q_{1}+Q_{2}-x-y\right) f(x, y) d x d y\right] \\
& +v_{2} \int_{0}^{Q_{2}}\left(Q_{2}-y\right) f_{2}(y) d y
\end{aligned}
$$

Proposition 1 Object function $P\left(Q_{1}, Q_{2}\right)$ is strictly conjointly concave and continuous in $\left(Q_{1}, Q_{2}\right)$, so there exists the optimal order quantity to get the maximal revenue.

Proof. From above assumption, we know 
$r_{1} \geq r_{2} \geq v_{1} \geq v_{2}, c_{1} \geq c_{2}$, and $f(x, y) \geq 0, f_{1}(x) \geq 0$, $f_{2}(y) \geq 0$ the first order and second order conditions are:

$$
\begin{gathered}
a\left(Q_{1}, Q_{2}\right)=\frac{\partial^{2} P}{\partial Q_{1}{ }^{2}}=-\left(r_{1}-r_{2}\right) f_{1}\left(Q_{1}\right)- \\
\left(r_{2}-v_{1}\right) \int_{0}^{Q_{2}} f\left(Q_{1}, y\right) d y-\left(r_{2}-r_{1}\right) \int_{0}^{Q_{1}} f\left(x, Q_{1}+Q_{2}-x\right) d x \\
b\left(Q_{1}, Q_{2}\right)=\frac{\partial^{2} P}{\partial Q_{1} \partial Q_{2}}=\left(v_{1}-r_{2}\right) \int_{0}^{Q_{1}} f\left(x, Q_{1}+Q_{2}-x\right) d x \\
c\left(Q_{1}, Q_{2}\right)=\frac{\partial^{2} P}{\partial Q_{2} \partial Q_{1}}=\left(v_{1}-r_{2}\right) \int_{0}^{Q_{1}} f\left(x, Q_{1}+Q_{2}-x\right) d x \\
d\left(Q_{1}, Q_{2}\right)=\frac{\partial^{2} P}{\partial Q_{2}^{2}}=-\left(r_{2}-v_{2}\right) f_{2}\left(Q_{2}\right)- \\
\left(r_{2}-v_{1}\right) \int_{0}^{Q_{1}} f\left(x, Q_{1}+Q_{2}-x\right) d x \\
+\left(r_{2}-v_{1}\right) \int_{0}^{Q_{1}} f\left(x, Q_{2}\right) d x
\end{gathered}
$$

so $a-b=$

$$
\begin{gathered}
-r_{1} f_{1}\left(Q_{1}\right)+r_{2} \int_{Q_{2}}^{\infty} f\left(Q_{1}, y\right)+v_{1} \int_{0}^{Q_{2}} f\left(Q_{1}, y\right) d y \\
\leq-r_{1} f_{1}\left(Q_{1}\right)+r_{1} \int_{Q_{2}}^{\infty} f\left(Q_{1}, y\right)+r_{1} \int_{0}^{Q_{2}} f\left(Q_{1}, y\right) d y \\
=-r_{1} f_{1}\left(Q_{1}\right)+r_{1} \int_{0}^{\infty} f\left(Q_{1}, y\right) d y<0 \\
d-b=-r_{2} \int_{Q_{1}}^{\infty} f\left(x, Q_{2}\right) d y-v_{1} \int_{0}^{Q_{1}} f\left(x, Q_{2}\right) d x+v_{2} f_{2}\left(Q_{2}\right) \\
<-v_{2} \int_{Q_{1}}^{\infty} f\left(x, Q_{2}\right) d x-v_{2} \int_{0}^{Q_{1}} f\left(x, Q_{2}\right) d x+v_{2} f_{2}\left(Q_{2}\right) \\
=-v_{2} \int_{0}^{\infty} f\left(x, Q_{2}\right) d x+v_{2} f_{2}\left(Q_{2}\right)<0
\end{gathered}
$$

Besides, from formulas, we can get $c=\frac{\partial^{2} P}{\partial Q_{2} \partial Q_{1}}$

$$
=\left(v_{1}-r_{2}\right) \int_{0}^{Q_{1}} f\left(x, Q_{1}+Q_{2}-x\right) d x=b<0
$$

and $a<b=c<0, d<b=c<0$. Therefore $a d>b c$, and $a d-b c>0$.

$$
\frac{\partial^{2} P}{\partial Q_{1}^{2}} \cdot \frac{\partial^{2} P}{\partial Q_{2}^{2}}-\frac{\partial^{2} P}{\partial Q_{1} \partial Q_{2}} \cdot \frac{\partial^{2} P}{\partial Q_{2} \partial Q_{1}}>0
$$

Base on the judge principle of binary function we know the object function $P\left(Q_{1}, Q_{2}\right)$ is strictly concave.

\section{Solution and analysis of model}

The idea of the paralleled semi-extension rule based algorithm is as follows. Firstly, the algorithm decomposes the maximum terms space of the clause set into several partial maximum terms spaces, which convert the SAT problem of the clause set into the SAT problem of the partial maximum terms spaces. If there is a certain partial maximum terms space that is satisfied, then the clause set is satisfied. If all the partial maximum terms spaces are unsatisfied, then the clause set is unmet. In this section, we will analyze the model and solve the optimal order quantity of each product, and then, we will analyze and prove the relationships among wholesale price, retail price, salvage value, average demand of each product and optimal order quantity.

Due to the function $P\left(Q_{1}, Q_{2}\right)$ is concave, optimal order quantity can be computed out by following equations.

$$
\left\{\begin{array}{l}
\frac{\partial P}{\partial Q_{1}}=-\left(r_{1}-r_{2}\right) \int_{0}^{Q_{1}} f_{1}(x) d x-\left(r_{2}-v_{1}\right) \\
\int_{0}^{Q_{1}} \int_{0}^{Q_{1}+Q_{2}-x} f(x, y) d y d x+\left(r_{1}-c_{1}\right)=0 \\
\frac{\partial P}{\partial Q_{2}}=-\left(r_{2}-v_{2}\right) \int_{0}^{Q_{2}} f_{2}(x) d x-\left(r_{2}-v_{1}\right) \\
\int_{0}^{Q_{1}} \int_{Q_{2}}^{Q_{1}+Q_{2}-x} f(x, y) d y d x+\left(r_{2}-c_{2}\right)
\end{array}\right.
$$

If $G\left(Q_{1}, Q_{2}\right)=\int_{0}^{Q_{1}} \int_{0}^{Q_{1}+Q_{2}-x} f(x, y) d y d x$, and then $F_{1}\left(Q_{1}^{*}\right)+\frac{r_{2}-v_{1}}{r_{1}-r_{2}} G\left(Q_{1}^{*}, Q_{2}^{*}\right)=\frac{r_{1}-c_{1}}{r_{1}-r_{2}}$, and

$$
F_{2}\left(Q_{2}^{*}\right)+\frac{r_{2}-v_{1}}{r_{1}-v_{2}}\left[G\left(Q_{1}^{*}, Q_{2}^{*}\right)-F\left(Q_{1}^{*}, Q_{2}^{*}\right)\right]=\frac{r_{2}-c_{2}}{r_{2}-v_{2}}
$$

$Q_{1}^{*}$ and $Q_{2}^{*}$ denote the optimal order quantity of each product respectively, $F_{i}\left(Q_{i}^{*}\right)(i=1,2)$ denote the probability of using product $i$ to satisfy customer demand when the available quantity of seller are $Q_{i}^{*}$, and it also stands for the service level to customers with product $i$, we can denote it as:

$$
F_{1}\left(Q_{1}^{*}\right)=\int_{0}^{Q_{1}^{*}} f_{1}(x) d x, F_{2}\left(Q_{2}^{*}\right)=\int_{0}^{Q_{2}^{*}} f_{2}(x) d x
$$

$G\left(Q_{1}^{*}, Q_{2}^{*}\right)$ is the probability of product 1 substituting for product 2 when the former have surplus inventory and can substitute the latter, which can improve the service level for product 2 , so we call it as substitution service level. $G\left(Q_{1}^{*}, Q_{2}^{*}\right)-F\left(Q_{1}^{*}, Q_{2}^{*}\right)$ is the probability of product 1 substitute product 2 when the latter one stock out, it eliminates the probability of product with surplus inventory which can substitute product 2 to satisfy the demand for product 2, so it stands for the real substitution service level. $F\left(Q_{1}^{*}, Q_{2}^{*}\right)=\int_{0}^{Q_{1}^{*}} \int_{0}^{Q_{2}^{*}} f(x, y) d y d x$ means the substitution strategy is not necessary for the seller, all demands for two products can be satisfied. $F_{2}\left(Q_{2}^{*}\right)+G\left(Q_{1}^{*}, Q_{2}^{*}\right)-F\left(Q_{1}^{*}, Q_{2}^{*}\right)$ is the probability that all demand of product 2 can be satisfied, and it includes the probability of using product 1 substitute for product 2 . Finally, we can get optimal order quantity of product 1 
and product 2 .

Property 1 The optimal order quantity of either one product is negatively correlated with its unit wholesale price, but positively correlated with unit wholesale price of another product, $\frac{\partial Q_{1}^{*}}{\partial c_{1}}<0, \frac{\partial Q_{2}^{*}}{\partial c_{1}}>0, \frac{\partial Q_{1}^{*}}{\partial c_{2}}>0, \frac{\partial Q_{2}^{*}}{\partial c_{2}}<0$.

Proof. Differentiating equation (1) with respect to $c_{1}$, where $a^{*}, b^{*}, c^{*}, d^{*}$ is the value of $a=\frac{\partial^{2} P}{\partial Q_{1}{ }^{2}}$, $b\left(Q_{1}, Q_{2}\right)=\frac{\partial^{2} P}{\partial Q_{1} \partial Q_{2}}, c=\frac{\partial^{2} P}{\partial Q_{2} \partial Q_{1}}, d\left(Q_{1}, Q_{2}\right)=\frac{\partial^{2} P}{\partial Q_{2}^{2}}$ at $\left.Q_{1}^{*}, Q_{2}^{*}\right)$. It is easy to get $\frac{\partial Q_{1}^{*}}{\partial c_{1}}=\frac{d^{*}}{a^{*} d^{*}-b^{*} c^{*}}<0$ and $\frac{\partial Q_{2}^{*}}{\partial c_{1}}=\frac{-c^{*}}{a^{*} d^{*}-b^{*} c^{*}}>0$. Similarly, we can get: $\frac{\partial Q_{1}^{*}}{\partial c_{2}}=\frac{-b^{*}}{a^{*} d^{*}-b^{*} c^{*}}>0$ and $\frac{\partial Q_{2}^{*}}{\partial c_{2}}=\frac{a^{*}}{a^{*} d^{*}-b^{*} c^{*}}<0$.

Property 1 is coincident with real situation. When the unit purchase price of one product increases, the seller should purchase fewer quantity but purchase more quantity of another product.

Property 2 Optimal order quantity of either one product is positively correlated with its unit sale price, and the optimal order quantity of product 2 is negatively correlated with product 1 ,

$$
\frac{\partial Q_{1}^{*}}{\partial p_{1}}>0, \frac{\partial Q_{2}^{*}}{\partial p_{2}}>0, \frac{\partial Q_{2}^{*}}{\partial p_{1}}<0
$$

Proof. For $r_{1}=p_{1}-\pi_{1}$, and equation (1), we know that if we want to obtain the relationships between the optimal order quantity of one product and its sale price, we can get it from $r_{1}=p_{1}-\pi_{1}$, i.e. $\frac{\partial Q_{1}^{*}}{\partial p_{1}}=\frac{\partial Q_{1}^{*}}{\partial r_{1}}, \frac{\partial Q_{1}^{*}}{\partial p_{2}}=\frac{\partial Q_{1}^{*}}{\partial r_{2}}$. Differentiating the two equations of (1) with $r_{1}$, and then $\frac{\partial Q_{1}^{*}}{\partial p_{1}}=\frac{d^{*}\left(-1+F\left(Q_{1}^{*}\right)\right)}{a^{*} d^{*}-b^{*} c^{*}}>0, \frac{\partial Q_{2}^{*}}{\partial p_{1}}=\frac{-c^{*}\left(-1+F\left(Q_{1}^{*}\right)\right)}{a^{*} d^{*}-b^{*} c^{*}}<0$.

For the same reason process, we can get $\frac{\partial Q_{2}^{*}}{\partial p_{2}}=\frac{\partial Q_{2}^{*}}{\partial r_{2}}>0$. So the sellers should purchase more products when its sale price increases. But when the sale price of both products increase, seller should purchase more quantity of product 1 but less quantity of product 2 , which is the optimal strategy.

Property 3 The optimal order quantity of one product is positively correlated with its unit net salvage value, while the optimal order quantity of product 1 is negatively correlated with unit net salvage value of product 2 , $\frac{\partial Q_{1}^{*}}{\partial v_{1}}>0, \frac{\partial Q_{2}^{*}}{\partial v_{2}}>0, \frac{\partial Q_{1}^{*}}{\partial v_{2}}<0$.

Proof. Differentiating equation (1) with respect to $v_{1}$, and for $a^{*}<b^{*}=c^{*}, d^{*}<b^{*}=c^{*}<0$, we can get $\frac{\partial Q_{1}^{*}}{\partial v_{2}}=\frac{b^{*} F_{2}\left(Q_{2}^{*}\right)}{a^{*} d^{*}-b^{*} c^{*}}<0, \frac{\partial Q_{2}^{*}}{\partial v_{2}}=\frac{-a^{*} F_{2}\left(Q_{2}^{*}\right)}{a^{*} d^{*}-b^{*} c^{*}}>0$.

From the above, we know $\frac{\partial Q_{1}^{*}}{\partial v_{1}}>0, \frac{\partial Q_{2}^{*}}{\partial v_{2}}>0$, $\frac{\partial Q_{1}^{*}}{\partial v_{2}}<0$, which indicates that we should increase order quantity of either one product when its unit net salvage value increase, and we should decrease the order quantity of product 2 and decrease the order quantity of product 1 when the net salvage value of product 2 increase. So far, we have researched some relationship between purchase price, sale price, net salvage value and optimal order quantity, leading to three important conclusions. Now, if we assume the demand of two products observe joint norm distribution function. $\mu_{1}, \mu_{2}$ denote the respective average demand of product 1 and $2, \sigma_{1}, \sigma_{2}$ denote the variance, $\sigma_{1}>0, \sigma_{2}>0,|r|<1$. Since we can substitute product 2 with product 1 when the former one stock out, so the demand of two products are not independent, i.e. $r \neq 0$, and then we can get some different conclusions, as following.

Property 4 The optimal order quantity of one product is positively correlated with its average demand but independent with the average demand of another product, i.e.

$$
\frac{\partial Q_{1}^{*}}{\partial \mu_{1}}>0, \frac{\partial Q_{2}^{*}}{\partial \mu_{1}}=0, \frac{\partial Q_{1}^{*}}{\partial \mu_{2}}=0, \frac{\partial Q_{2}^{*}}{\partial \mu_{2}}>0
$$

Proof. Differentiating equation (1) with respect to $\mu_{1}$, it is easy to get

$$
\frac{\partial Q_{1}^{*}}{\partial \mu_{1}}=1, \frac{\partial Q_{2}^{*}}{\partial \mu_{1}}=0, \frac{\partial Q_{1}^{*}}{\partial \mu_{2}}=0, \frac{\partial Q_{2}^{*}}{\partial \mu_{2}}=1
$$

Property 5 The optimal order quantity of product 1 is positively correlated with the demand variance of product 2 , and the optimal order quantity of product 2 is negatively correlated with demand variance of product $1, \frac{\partial Q_{2}^{*}}{\partial \sigma_{1}}<0, \frac{\partial Q_{1}^{*}}{\partial \sigma_{2}}>0$.

Proof. Differentiating equation (1) with respect to $\sigma_{1}$, and for $v_{1} \geq v_{2}$,

$$
\begin{aligned}
& \frac{\partial Q_{1}^{*}}{\partial \sigma_{2}}>\frac{\left(r_{2}-v_{1}\right)}{a^{*} d^{*}-b^{*} c^{*}} \int_{0}^{Q_{1}^{*}} \frac{Q_{1}^{*}-x}{\sigma_{2}} f\left(x, Q_{1}^{*}+Q_{2}^{*}-x\right) d x \\
& \quad \times\left[\left(r_{2}-v_{1}\right)\left(f_{2}\left(Q_{2}^{*}\right)-\int_{0}^{Q_{1}^{*}} f\left(x, Q_{2}^{*}\right) d x\right)\right] \\
& >\frac{\left(r_{2}-v_{1}\right)}{a^{*} d^{*}-b^{*} c^{*}} \int_{0}^{Q_{1}^{*}} \frac{Q_{1}^{*}-x}{\sigma_{2}} f\left(x, Q_{1}^{*}+Q_{2}^{*}-x\right) d x \times \\
& \quad\left[\left(r_{2}-v_{1}\right)\left(f_{2}\left(Q_{2}^{*}\right)-\int_{0}^{\infty} f\left(x, Q_{2}^{*}\right) d x\right)\right]=0 \\
& \text { so } \frac{\partial Q_{2}^{*}}{\partial \sigma_{1}}<0, \frac{\partial Q_{1}^{*}}{\partial \sigma_{2}}>0 .
\end{aligned}
$$

\section{Models comparability}

Discussion about optimal order quantity We will compare our model with the newsboy model. In equation (1), Let $r_{2}=v_{1}\left(r_{2}=p_{2}+\pi_{2}, v_{1}=s_{1}-h_{1}\right)$, the equation (1) can be $F_{1}\left(Q_{1}^{*}\right)=\frac{r_{1}-c_{1}}{r_{1}-r_{2}}$ and $F_{2}\left(Q_{2}^{*}\right)=\frac{r_{2}-c_{2}}{r_{2}-v_{2}}$.

This equation could be derived from the news-boy model. The assumption $r_{2}=v_{1}$ indicates the seller don't take the substitution strategy to satisfy customer demand. It's clear that newsboy model is the special case of this model. We will make further analysis for the model 
before and after taking substitution strategy. The analysis in the above tells us that the model would be newsboy model if sellers don't take substitution strategy. Now we denote $\left(Q_{1}^{*}, Q_{2}^{*}\right)$ as the optimal order quantity of two products after taking substitution strategy and denote $\left(Q_{1}^{*^{\prime}}, Q_{2}^{*^{\prime}}\right)$ as the optimal order quantity of two products when sellers give up taking substitution strategy, and when taking $r_{2}=v_{1}$ into equation (1), we can get: $F_{1}\left(Q_{1}^{*^{\prime}}\right)=\frac{r_{1}-c_{1}}{r_{1}-v_{1}}, F_{1}\left(Q_{2}^{*}\right)=\frac{r_{2}-c_{2}}{r_{2}-v_{2}}$.

When $r_{2}=v_{1}$ and $p_{2}=v_{1}-\pi_{2}$, the substitute strategy is the same strategy that sellers don't take it, because the profit in each condition is equal. Here, we don't have to take substitution strategy. We will discuss the variation of optimal order quantity and expect total revenue in order to make the theory more realistic and complete.

For $G\left(Q_{1}, Q_{2}\right)=\int_{0}^{Q_{1}} \int_{0}^{Q_{1}+Q_{2}-x} f(x, y) d y d x \quad$ and $f(x, y) \geq 0$, we can obtain

$$
\begin{gathered}
G\left(Q_{1}, Q_{2}\right)=\int_{0}^{Q_{1}} \int_{0}^{Q_{1}+Q_{2}-x} f(x, y) d y d x \\
\leq \int_{0}^{Q_{1}} \int_{0}^{\infty} f(x, y) d y d x=F\left(Q_{1}\right) \\
G\left(Q_{1}, Q_{2}\right)=\int_{0}^{Q_{1}} \int_{0}^{Q_{1}+Q_{2}-x} f(x, y) d y d x \\
\geq \int_{0}^{Q_{1}} \int_{0}^{Q_{2}} f(x, y) d y d x=F\left(Q_{1}, Q_{2}\right)
\end{gathered}
$$

Clearly, $G\left(Q_{1}, Q_{2}\right) \leq F\left(Q_{1}\right), G\left(Q_{1}, Q_{2}\right) \geq F\left(Q_{1}, Q_{2}\right)$, and then $0<\frac{r_{1}-c_{1}}{r_{1}-v_{1}} \leq F_{1}\left(Q_{1}^{*}\right)<1$. Similarly, we can get $F_{1}\left(Q_{1}^{*^{\prime}}\right) \leq F_{1}\left(Q_{1}^{*}\right), F_{2}\left(Q_{2}^{*}\right) \leq F_{2}\left(Q_{2}^{*^{\prime}}\right), Q_{2}^{*} \leq Q_{2}^{*^{\prime}}$.

From above equations, we can know that sellers could purchase more product 1 and fewer product 2 when the substitution strategy is adopted. In fact, when the high-end product can substitute for the low-end product to meet the emergency demand, the high-end product should be ordered in more quantity, but less quantity of low-end product.

Discussion about total revenue $P^{\prime}\left(Q_{1}, Q_{2}\right)$, and $\left(Q_{1}^{*^{\prime}}, Q_{2}^{*^{\prime}}\right)$ denote the total revenue and the optimal order quantity respectively when the substitution strategy is not adopted. From above, definitions, we can obtain $P\left(Q_{1}^{*}, Q_{2}^{*}\right) \geq P\left(Q_{1}^{*^{\prime}}\right.$,

$\left.Q_{2}^{*^{\prime}}\right)$. For $r_{2}=p_{2}-\pi_{2} \geq v_{1}$ and

$$
\begin{gathered}
P\left(Q_{1}^{*^{\prime}}, Q_{2}^{*^{\prime}}\right)-P^{\prime}\left(Q_{1}^{*^{\prime}}, Q_{2}^{*^{\prime}}\right)=\left(r_{2}-v_{1}\right) \times \\
{\left[\int_{0}^{Q_{1}^{*^{\prime}}} \int_{Q_{2}^{*}}^{Q_{1}^{*^{\prime}}+Q_{2}^{*^{\prime}}-x}\left(y-Q_{2}^{*}\right) f(x, y) d y d x+\right.} \\
\left.\int_{Q_{1}^{*}+Q_{2}^{*}-x}^{Q_{2}^{*}}\left(Q_{1}^{*}-x\right) f(x, y) d y d x\right]
\end{gathered}
$$

then we can know $P\left(Q_{1}^{*^{\prime}}, Q_{2}^{*^{\prime}}\right) \geq P^{\prime}\left(Q_{1}^{*^{\prime}}, Q_{2}^{*^{\prime}}\right)$, which indicates that substitution strategy can improve total revenue of seller.

(1)Discussion about service level

$G\left(Q_{1}^{*}, Q_{2}^{*}\right)-F\left(Q_{1}^{*}, Q_{2}^{*}\right)$ denote the real service level, which is the probability of using product 1 to substitute for product 2 to satisfy the demand for product 2 once product 2 stock out. The probability have deducted the probability of product 2 which can satisfy the customers' demand for them though product 1 have surplus inventory and can substitute product 2. So $F_{2}\left(Q_{2}^{*}\right)+G\left(Q_{1}^{*}, Q_{2}^{*}\right)-F\left(Q_{1}^{*}, Q_{2}^{*}\right) \geq F_{2}\left(Q_{2}^{*}\right)$. When the product 1 can substitute for the product 2 to meet demand of product 2, and if the seller take the substation strategy, then the service level can be improved, especially when the product 2 stock out.

\section{Conclusion}

In this paper, we studied some optimal inventory problems of two downward substituted products in single period with stochastic demands. We developed some mathematic models of maximal revenue when the seller adopted substitution strategy and proofed the relative propositions. By studying the relationships between wholesale price, sale price, net salvage value and optimal order quantity, we obtained some useful conclusions which indicate that the substitution strategy can improve total revenue and service level and it played an important role in the whole operation systems. At the same time, we pointed out that the model would be newsboy model if sellers didn't take substitution strategy. Besides, some analysis for the mathematic models showed that the optimal order quantity of high-end product was positively correlated with the demand variance of low-end one, but the optimal order quantity of low-end product was negatively correlated with demand variance of high-end product. Furthermore, the optimal order quantity of one product was positively correlated with its average demand but independent with the average demand of another product. So in the real sale campaign,when one product stock out, if sellers substitute this kind of product with another higher-end product, they can get more profits and obtain more customers.

\section{References}

[1] R. Anupindi, M. Dada, and S.Gupta, Estimation of con-sumer demand with stock-out based substitution: an ap-plication to vending machine products. Marketing Science 17, 406- 423, (1998).

[2] M. Khouja, S.Goyal, A review of the joint replenishment problem literature: 1989-2005. European Journal of Operational Research 186, 1-16, (2008).

[3] E. Hassini. Storage space allocation to maximize interreplenishment times. Computers and Operations Research 32, 3191-3207, (2005). 
[4] G. Kuk. Effectiveness of vendor-managed inventory in the electronics industry: determinants and outcomes. Information and Management 41, 645-654, (2004).

[5] Y. Dong, K.Xu, A supply chain model of vendor managed inventory. Transportation Research Part E 38, 75-95, (2002).

[6] Y. Dong, K. Xu, M.Dresner, Environmental determinants of VMI adoption: an explorative analysis. Transportation Research Part E 43, 355-369, (2007).

[7] D. Huang, Q. H. Zhao, C. Cheng, Simulation based optimization of inventory model with products substitution, Innovative Quick Response Programs in Logistics and Supply Chain Management. International Handbooks on Information Systems, 3, 297-312, (2010).

[8] M. Braglia, L. Zavanella, Modelling an industrial strategy for inventory management in supply chains. International Journal of Production Research 41, 3793-3808, (2003).

[9] B. Deniz, I. Karaesmen, A. Scheller Wolf, Managing Perishables with Substitution: Inventory Issuance and Replenishment Heuristics. Manufacturing and Service Operation Management 12, 319-329, (2010).

[10] R. Koster, T. Leduc, H. J. Roodbergen, Design and control of warehouse order picking. European Journal of Operational Research 182, 481-501, (2007).

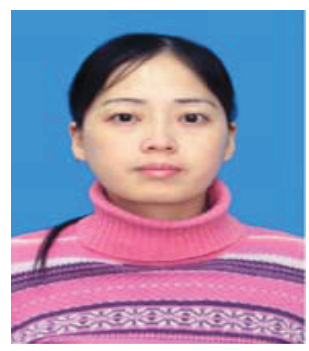

Yan-hong Qin Sichuan Province, China. Birthdate: Nov, 1981. Work as associate professor in Management School of Chongqing Jiaotong University, and research interests on mass customization and supply chain management.

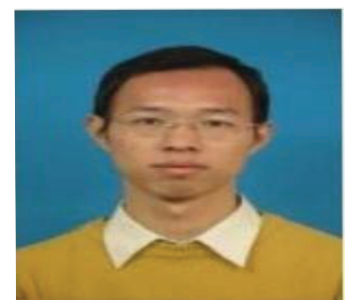

Management.

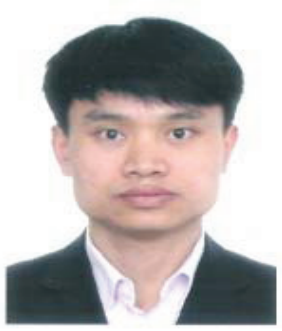

\section{Xing-hong}

Qin Hubei Province,

China. Birthdate: January, 1985 is Management Theory and industry Engineering Ph.D. in school of economics and management, Tongji University. And research interests on operation management and quality

Qing Wu Hubei Province, China. Birthdate: Oct, 1977. Work as assistant professor in Management and Economics School of Electronic Science and Technology University, and research interests on supply chain management. 